\title{
Extraction of Some Typical Heavy Metals with a Multidentate Soft-Ligand 2,6-Bis (5,6-dipropyl-1,2,4-triazine-3-yl)pyridine
}

\author{
Sun Zhi-meng, Cui Yu*, Sun Guo-xin, Zhou He-fang \\ School of Chemistry and Chemical Engineering, \\ University of Jinan \\ Jinan, 250022, China \\ *chm_cuiy@ujn.edu.cn; Sunzhimeng163@163.com; Sun-guo-xin@hotmail.com; zhou_hefang@126.com
}

\begin{abstract}
-2, 6-bis (5,6-dipropyl-1,2,4-triazine-3-yl) pyridine (BDPTP) was synthesized with 2, 6 - dimethyl pyridine and ethyl butyrate as raw materials. And characterized by IR, 1HNMR and element analysis etc. The extraction performance of this kind of complexes for four kinds of cations, $\mathrm{Cu}(\mathrm{II})$, $\mathrm{Cd}(\mathrm{II}), \mathrm{Pb}(\mathrm{II}), \mathrm{Ni}(\mathrm{II})$ is studied in hydrochloric acid system. The results show that the extraction rate of cadmium chloride with BDPTP in dichloromethane can reach to $97.25 \%$. It is meaningful to cadmium chloride wastewater treatment.
\end{abstract}

Keywords-2, 6-bis (5,6-dipropyl-1,2,4-triazine-3-yl) pyridine, Solvent extraction, Heavy metal wastewater

\section{INTRODUCTION}

It is well known that heavy metals such as cadmium and copper in environments pose a serious threat to plants, animals and even human beings because of their bioaccumulation, nonbiodegradable property and toxicity even at low concentration [1]. In general, the pollution caused by heavy metals has detrimental effect on the environment all over the world. For example, a variety of toxic effects on aquatic organisms can be produced by endangering ecosystems; human health can be directly or indirectly influenced by multiple channels such as touching with skin, drinking water, and food chain. In addition, in agro-ecological environment, especially in soils, the phenomenon of heavy metals pollution is now quite common. Heavy metals cause great harm to the crop growth, yield and quality. So the removal of heavy metals, such as mercury, lead, zinc, copper, cadmium, and chromium, from natural waters or soils has attracted considerable attention [2].

Currently, the heavy metal wastewater treatment methods are mainly three types: the first method of heavy metal ions in wastewater is removed by a chemical reaction, including neutralization precipitation, sulfide precipitation, ferrite co-precipitation method, chemical reduction, electrochemical reduction method and polymer heavy metal chelating agent method. The second category is that heavy metals in the conditions that wastewater does not change its chemical form to adsorption, concentration, separation methods, including adsorption, solvent extraction, evaporation and solidification method, ion exchange and membrane separation. The third category is the use of microorganisms or plants flocculation, absorption, accumulation, and so on enrichment method for removing heavy metals from wastewater, including biological flocculation, ecological restoration and plant biochemical methods [3].

Solvent extraction method is useful in the purification of wastewater. It not only removes the heavy metal from waste water,but also recover the useful materials.

So solvent extraction method used in the environmental pollution control has become a popular technology, especially in the case that the wastewater using conventional biochemical methods is difficult to restore, or waste is at low concentration, or some useful materials in the waste need to be recycled. Solvent extraction method, with high efficiency and, energy-saving advantages, continues to be favored by the world science and technology workers. Many have found biodegradable pollutants, and even some environmental contaminants, such as chromium, nickel, lead, cadmium and other heavy metals, in the role of the solvent extraction method can be significantly removed[4].

Dialkyl-BTP as shown in Fig. 1 is a multicoordinate soft-ligand containing seven nitrogen atoms. The results showed that it had an excellent extraction ability and selectivity for trivalent MAs(III) over all of the REs(III)[57]. Similar to dialkyl-BTP, some derivatives of bipyridines also exhibited the same extraction properties for MAs(III) and REs(III)[8-10]. On the other hand, in terms of the traditional Lewis theory of acid-base reactions, nitrogen in dialkyl-BTP or the derivative of bipyridine has much better coordination ability for the elements of d-block in the periodic table of elements. But few works studies the extraction of the ds-block elements with this series ligand up to now. It is therefore reasonable that some heavy metals $\mathrm{Cu}$ (II), Cd (II), and Pb (II) might also be extracted with BTP. From this viewpoint, utilizing the soft-base principle and experimental method of the solvent extraction to investigate the complexation of Cd (II) with dialkyl-BTP is meaningful. The complexation of Cd (II) with dialkyl-BTP or the derivatives of bipyridines either in chromatographic separation with a stationary phase or in solvent extraction has not been reported yet. The purpose of the present work was to obtain some valuable experimental data by solvent extraction. The main objective was focused on: (1) synthesis of a new multidentate soft-ligand 2,6-bis(5,6-diPropyl-1,2,4triazine-3-yl)pyridine (BDPTP),(2) investigation of the extraction properties of some typical heavy metals $\mathrm{Pb}$ (II), $\mathrm{Cd}(\mathrm{II}), \mathrm{Cu}(\mathrm{II})$, and $\mathrm{Ni}(\mathrm{II})$ with a BDPTP in diluents 
containing $20 \%$ 1-octanol and $80 \%$ sulfonated kerosene. The effects of the coion, the $\mathrm{NaCl}$ concentration in the range of 0.1 to $0.5 \mathrm{M}$, and solvent effects were investigated. The possibility and feasibility of application of extraction system in partitioning of $\mathrm{Cd}(\mathrm{II})$ from waste water were evaluated.<smiles>[R]c1nnc(-c2cccc(-c3nnc([R])c([R])n3)n2)nc1[R]</smiles>

Figure 1. Chemical structure of 2,6-bis(5,6-dialkyl-1,2,4-triazine-3yl)pyridine (dialkyl-BTP).

\section{EXPERIMENTAL PROCEDURE}

\section{A. Materials and Instrument}

The metal chloridates $\mathrm{CuCl}_{2} \cdot 2 \mathrm{H}_{2} \mathrm{O}, \mathrm{CdCl}_{2}, \mathrm{PbCl}_{2}, \mathrm{NiCl}_{2}$ used were analytical grade. 2, 6 - dimethyl pyridine and ethyl butyrate were purchased from Energy Chemical and used as received. The diluents, 1-octanol and sulfonated kerosene, used in organic phase were available commercial products. To avoid the formation of the third phase in solvent extraction, a mixture composed of $20 \%$ 1-octanol and $80 \%$ sulfonated kerosene was used as the organic phase to dissolve BDPTP. Based on the excellent solubility of BDPTP, no any additive was used in organic phase. The other organic and inorganic reagents were of analytical grade and were used without further treatment.

${ }^{1} \mathrm{H}$ NMR spectra were recorded on a Bruker DPX400NMR spectrometer. IR spectroscopy were performed on a US Bio-Rad Company Perkin Elmer FTIR spectrophotometer. Ion concentration were detected by atomic absorption got from US PE Company.

A soft-ligand with multinitrogen donors, 2, 6-bis (5,6dipropyl-1,2,4-triazine-3-yl)pyridine (BDPTP) as shown in Fig. 2, was synthesized quantitatively by the multistep reactions.

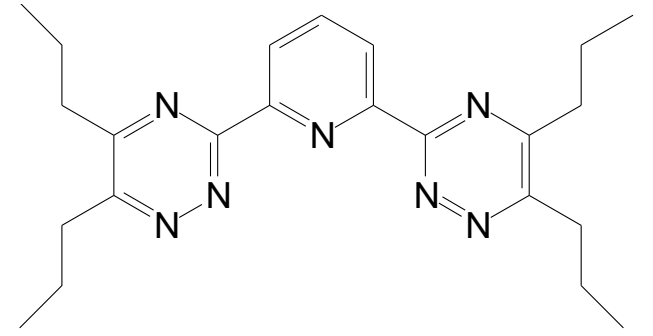

Figure 2. Molecular structure of 2, 6-bis (5,6-dipropyl-1,2, 4-triazine-3-yl)pyridine (Prop-BTP).

\section{B. Synthesis of BDPTP}

The preparation of BDPTP was performed through three steps.

The first step:

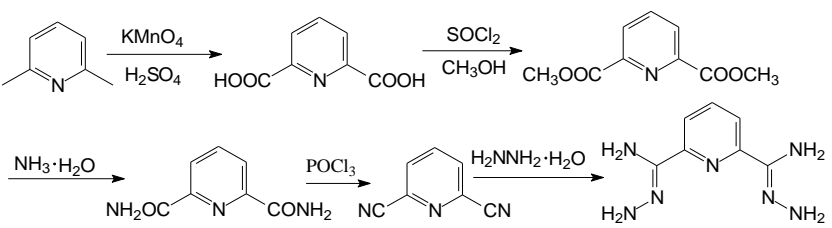

The second step:

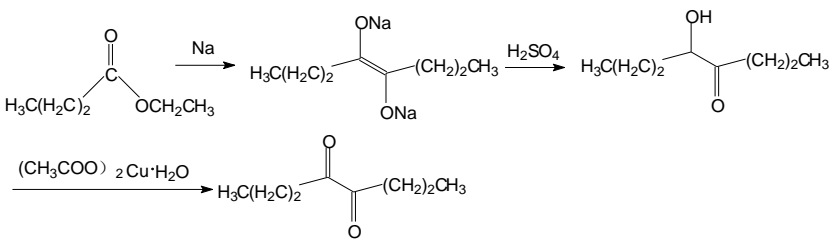

The third step:

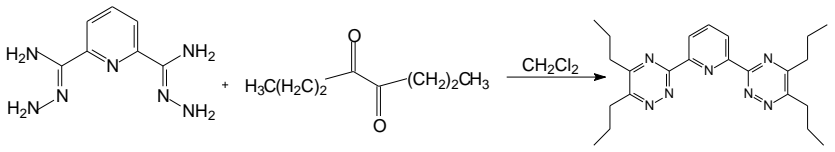

It was described as: (1) 2, 6-dimethyl pyridine as raw material, through oxidation, esterification, amination, dehydration, and reaction with $85 \%$ of hydrazine hydrate generation 2, 6-pyridinedicarboxamide dihydrazone ${ }^{1} \mathrm{H}$ NMR $\left(25^{\circ} \mathrm{C}\right.$, DMSO):7.8 (d, 2H),7.64 (t, 1H), 6.05 (s, 4H), $5.25(\mathrm{~s}, 4 \mathrm{H})$.

(2) Using anhydrous diethyl ether as solvent, to a dry flask containing a magnetic stirring bar was added sodium sand. Then slowly added ethyl butyrate to stir mixture. Then reflux reaction $4 \mathrm{~h}$, After put in an ice bath, and reaction liquid droped slowly with $40 \%$ sulfuric acid, until will be transferred to the acid solution, and got butyroin reactant by hydrolysis. Then added $10 \%$ sodium bicarbonate to a neutral $\mathrm{pH}$, ceded the ether layer, drought with anhydrous sodium sulfate, spin steamed out of anhydrous diethyl ether, got butyroin rough.

In a $250 \mathrm{ml}$ dry flask added copper acetate and butyroin reflux reaction for $5 \mathrm{~h}$ in $70 \%$ acetic acid, then adding sodium chloride saturated, and used methylene chloride extraction organic phase, put in sodium bicarbonate to a neutral $\mathrm{pH}$, then add the anhydrous magnesium sulfate to dry for $6 \mathrm{~h}$. Normal pressure steam out of methylene chloride, and then in $70^{\circ} \mathrm{C}$ pressure distillation. Collecting fractions, get a $\alpha$-diketone $\mathrm{CH}_{3}\left(\mathrm{CH}_{2}\right)_{2} \mathrm{COCO}\left(\mathrm{CH}_{2}\right)_{2} \mathrm{CH}_{3} \cdot{ }^{1} \mathrm{H} \mathrm{NMR}\left(25^{\circ} \mathrm{C}\right.$, $\left.\mathrm{CDCl}_{3}\right): 2.43(\mathrm{t}, 2 \mathrm{H}), 1.68(\mathrm{~m}, 2 \mathrm{H}), 1.45(\mathrm{~m}, 4 \mathrm{H}), 0.94(\mathrm{~m}, 6 \mathrm{H})$.

(3) Synthesis of BDPTP through the reaction of 2,6pyridinedicarboxamide dihydrazone with $\mathrm{CH}_{3}\left(\mathrm{CH}_{2}\right)_{2} \mathrm{COCO}$ $\left(\mathrm{CH}_{2}\right)_{2} \mathrm{CH}_{3}$ in dichloromethane, carried out for $3 \mathrm{~h}$ at $313 \mathrm{~K}$ and then recrystallized with ethanol. The resultant BDPTP, a yellow product, was characterized by ${ }^{1} \mathrm{H}$ NMR. The purity of BDPTP was determined to be more than $98.5 \%$. ${ }^{1} \mathrm{H}$ $\operatorname{NMR}\left(25^{\circ} \mathrm{C}, \mathrm{CDCl}_{3}\right): 8.72(\mathrm{~d}, 2 \mathrm{H}), 8.06(\mathrm{t}, 1 \mathrm{H}), 3.06(\mathrm{t}, 4 \mathrm{H})$, $2.92(\mathrm{t}, 4 \mathrm{H}), 1.92(\mathrm{~m}, 8 \mathrm{H}), 1.08(\mathrm{~m}, 12 \mathrm{H})$.

\section{RESULTS AND DISCUSSION}

\section{A. Dependence of the Tested Metal Extractions on the Same Ion Effect}

To understand the extraction behavior of BDPTP, a 
mixed organic solvent composed of $20 \% 1$-octanol and $80 \%$ sulfonated kerosene was used to dissolve BDPTP. The dependence of the extraction of some typical heavy metal products $\mathrm{Cu}(\mathrm{II}), \mathrm{Cd}(\mathrm{II}), \mathrm{Ni}(\mathrm{II}), \mathrm{Pd}(\mathrm{II})$, with $\mathrm{BDPTP} / 20 \%$ 1octanol-80\% sulfonated kerosene in oscillation tube with a change in different concentrations of sodium chloride from 0.1 to $0.5 \mathrm{M}$ was investigated at $298 \mathrm{~K}$.

The results are shown in Fig. 3.

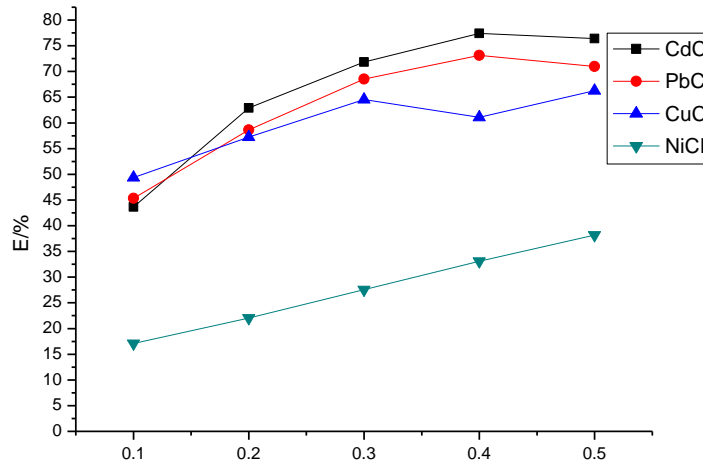

Figure 3. Sodium chloride concentration on the influence of different metal ions BDPTP extraction

We can see from the diagram, with the increase of concentration of sodium chloride, all kinds of ion extraction rate is also increasing, increase the rate of chloride ions can improve the extraction. The extraction of $\mathrm{Cd}(\mathrm{II})$ with BDPTP is best than others, the extraction rate can reach $77.4 \%$.

\section{B. Dependence of the Tested Metal Extractions on Solvent}

In order to study the effect of different solvent on the extraction, methylene chloride, chloroform, carbon tetrachloride, benzene, toluene, xylene were used as solvent, made up of different solvents extraction agent containing BDPTP 0.01 M. Cadmium Chloride and Copper Chloride were investigated in different solvents extraction rate at 298K.

The results are shown in table 1.

TABLE 1. DIFFERENT SOLVENTS ON THE EFFECT OF Cd(II) AND Cu(II) BDPTP EXTRACTION

\begin{tabular}{|c|c|c|}
\hline solvent & Cadmium chloride/E(\%) & Copper chloride/E(\%) \\
\hline Methylene chloride & 97.25 & 28.28 \\
\hline chloroform & 90.75 & 35.19 \\
\hline Carbon tetrachloride & 2.35 & 13.23 \\
\hline benzene & 79.25 & 27.95 \\
\hline toluene & 61.75 & 30.98 \\
\hline xylene & 4.25 & 27.2 \\
\hline
\end{tabular}

As can be seen from the table 1, methylene chloride as solvent on the extraction rate of cadmium chloride is highest, can reach $97.25 \%$. Two kinds of ions in carbon tetrachloride extraction rate is not high, this is due to the carbon tetrachloride has no polarity.

\section{CONCLUSION}

In this study, according to the literature we synthesized a new type of soft ligand compounds 2,6-bis(5,6-dipropyl1,2,4-triazine-3-yl)pyridine (BDPTP), and studied the extraction of cadmium, copper, lead and nickel[11-13]. The extraction behavior of heavy metal $\mathrm{Cd}(\mathrm{II}), \mathrm{Pd}(\mathrm{II}), \mathrm{Cu}(\mathrm{II})$, $\mathrm{Ni}(\mathrm{II})$ and BDPTP $/ 20 \%$ 1-octanol-80\% sulfonated kerosene with a change in different concentrations of sodium chloride from 0.1 to $0.5 \mathrm{M}$ was studied at $298 \mathrm{~K}$. Extraction rate increases with the increase of chloride ion concentration and can get best extraction effect of Cadmium. Solvent effect shows that when with dichloromethane as solvent, Cadmium extraction rate can reach $97.25 \%$. The extraction of Cadmium from wastewater has certain help, can effectively remove Cadmium from the wastewater.

\section{ACKNOWLEDGMENT}

The authors are grateful for the support from the National Natural Science Foundation of China (21077044, 21171069).

\section{REFERENCES}

[1] P. Trivedi, L. Axe, "Modeling $\mathrm{Cd}$ and $\mathrm{Zn}$ sorption to hydrous metaloxides", Environ.Sci. Technol.2000,pp. 2215-2223.

[2] W. Yantasee, C.L. Warner, T. Sangvanich, R.S. Addleman, T.G. Carter, R.J. Wiacek, G.E. Fryxell, C. Timchalk, M.G. Warner, "Removal of heavy metals from aqueous systems with thiol functionalized superparamagnetic nanoparticles", Environ. Sci. Technol. 2007,pp. 5114-5119.

[3] B.Feng,L.M.Zhang, "Research status and prospects of electroplating heavy metal wastewater treatment technology". Jiangsu environmental science and technology, 2004, vol. 17, pp. 38-40.

[4] F.Yuan,J.L.Gong,G.M.Zeng,Q.Y.Niu,H.Y.Zhang, "Adsorption of Cd (II) and Zn (II) from aqueous solutions using magnetic hydroxyapatite nanoparticles as adsorbents". Chemical Engineering Journal. 2010, pp.487-494.

[5] Z.Kolarik, U.Mü llich, F.Gassner, "Selective Extraction of Am(III) and $\mathrm{Eu}(\mathrm{III})$ by 2,6-Ditriazolyl- and 2,6-Ditriazinylpyridines". Solvent Extr. Ion Exch.1999, 17,pp.23-32.

[6] Z.Kolarik, U.Mü llich, F.Gassner, "Extraction of Am(III) and Eu(III) Nitrates by 2,6-Di(5,6-Dipropyl-1,2,4-Triazin-3-yl)Pyridines”. Solvent Extr. Ion Exch.1999, 17, pp.1155-1170.

[7] Z. Kolarik, "Extraction of Selected Mono- to Tetravalent Metal Ions by 2,6-Di(5,6-Dialkyl-1,2,4,-Triazin-3-yl)Pyridines". Solvent Extr. Ion Exch. 2003, 21,pp. 381-397.

[8] St. Mark, R.Foreman, J.Michael, J. H.Andreas, G.Madic, C. M. Weigl, "An Investigation into the Extraction of Americium(III) Lanthanides and d-Block Metals by 6,6-Bis-(5,6-Dipentyl-[1,2,4]-Triazin-3-yl)[2,2]Bipyridine(C5-BTBP)". Solvent Extr. Ion Exch.2005,23, pp. 645-662.

[9] T.Retegan, C. Ekberg, I.Dubois, "Extraction of Actinides with Different 6,6'-Bis(5,6-Dialkyl-1,2,4-Triazin-3-yl)-2,2'-Bipyridines (BTBPs)". Solent Extr. Ion Exch.2007, 25, pp.417-431.

[10] M. Nilsson, S.Andersson, F. Drouet, C.Ekberg, M.Foreman, M. Hudson, J. O.Liljenzin, D.Magnusson, G. Skarnemark, "Extraction Properties of 6,6'-Bis-(5,6-Di-pentyl-1,2,4-Triazin-3-yl)-2,2'-Bipyridinyl (C5-BTBP)".Solent Extr. Ion Exch.2006, 24, pp.299-318.

[11] H.B.Xiao,X.M.Tao,Y.C.Wang, "Dipicolinate as acceptor in D- $\pi-A$ chromophores: synthesis, characterization and fluorescence following single- and two-photon excitation".Tetrahedron Letters, 2008, pp.6819-6822.

[12] M.Polasek, P.Caravan, "Is Macrocycle a Synonym for Kinetic Inertness in $\mathrm{Gd}(\mathrm{III})$ Complexes? Effect of Coordinating and Noncoordinating Substituents on Inertness and Relaxivity of Gd(III) Chelates with DO3A-like Ligands".Inorganic chemistry,2013, Mar.21,pp.4084-4096. 
[13] E.Sagot, A. Le Roux, C. "Soulivet, Synthesis of linear and hyperbranched tetrazine-based polyhetarylene assemblies with high nitrogen content”. Tetrahedron ,2007,pp. 11189-11194. 